\title{
Analysis on the Development and Innovation Path of Chemical Fiber Industry Promoted by Digital Technology
}

\author{
Wang Fengyang ${ }^{1}$ \\ ${ }^{1}$ School of Economics and Management, Beijing Jiaotong University, Beijing, China
}

\begin{abstract}
With the development of digital technology and the continuous expansion of digital economy, digital industry is playing an important role in the development of traditional manufacturing industry. As an important field of modern industry, especially light industry, chemical fiber manufacturing industry has made a great contribution to the economic growth of people's livelihood in China. Through in-depth research and analysis of the innovation path of digital technology to promote the development of chemical fiber industry, this paper found that: The $1 \%$ growth of digital technology will drive the growth of chemical fiber industry by $0.58 \%$, this driving effect promotes the efficiency of process innovation, product innovation, marketing efficiency and management efficiency of the chemical industry, digital technology will enable the chemical fiber industry to break through the limitations of the traditional development mode in all links of the industrial chain and form a strong driving force for its sustainable development. Therefore, accelerating the in-depth integration of digital technology and chemical fiber industry is the key path for China's chemical fiber industry to resolve the current challenges in terms of price and supply chain relations and to achieve high-quality development.
\end{abstract}

\section{Introduction}

At present, we are at a historic juncture in the world's new round of technological revolution and the transformation of China's development mode. New technology revolutions with digital technologies such as big data, cloud computing, Internet of Things, and artificial intelligence at the core are accelerating the evolution and diffusion, and triggering changes in the business environment. In 2018, China's digital economy reached 31.3 trillion yuan and digital industrialization reached 6.4 trillion yuan, accounting for $7.1 \%$ of GDP. The demand for information consumption, investment in the digital economy, and digital trade are constantly being released, and the digital industry is developing rapidly. Digital technology has all the characteristics of general purpose technology (GPT). Through extensive integration and penetration of traditional industries, digital technology can increase its output and improve its production efficiency. Against this background, countries around the world have deployed the integration of digital technology and traditional industries, and China has also proposed strategies such as "Made in China 2025" to promote the digital transformation of traditional manufacturing. With the outbreak of the COVID-19 in 2020, the development of the global economy is restricted. Having digital solutions such as online office systems and flexible manufacturing technologies has become an important means for enterprises to quickly resume work and ensure operations. The superiority of digital technology further promotes the process of industrial digitization.

Chemical fiber industry is an important field of modern industrial production in China, and its contribution to national economy is indispensable. With the acceleration of industrialization, China's textile demand, which has been restrained by the shortage of resources for a long time, has expanded rapidly, which has greatly stimulated the development of chemical fiber manufacturing industry. Currently, chemical fiber production capacity accounts for $90 \%$ of the world. With the change of the world economic environment, the constant fluctuation of raw material price, the change of global textile industry chain supply and demand and the change of fiber consumption structure, the future development of chemical fiber industry is constantly challenged. The overall operation of China's chemical fiber industry is unbalanced, and the problems of product structure and cost control lead to the decline of industrial transfer competitiveness and the lack of technological innovation ability[1]. After the 13th Five-Year Plan, China has entered a new normal stage of economy, the chemical fiber industry has also entered a period of low-speed growth[2]. Japan is a country with relatively developed chemical fiber industry, and continuous technological innovation is the core driving force for Toray group, Diren group and Asahi chemical group to become century-old enterprises[3], thus, how to maintain innovation will be an important way to promote the development of this industry.

After the 21st century, digital technology has flourished in the world with lightning speed, promoting the continuous breakthrough of nanotechnology, driving 
the rapid development of the chemical fiber industry[4]. As one of the important factors of production, digital technology promotes the increase of output and economic growth of chemical fiber industry, the upgrading of production technology and the improvement of economic efficiency through innovation, it is regarded as an internal driving forces for the sustainable development of traditional industries. There are few studies on the role of digital technology to promote the development of chemical fiber industry, and relevant studies mainly concentrated on the application of the Internet[5], information management systems[6][7][8] and business process management[9][10]. This paper will start from the perspective of Schumpeter's five innovation approaches, explore the path of digital technology to promote the innovation and upgrading of chemical fiber industry, and research the mechanism of digital technology to chemical fiber industry.

\section{Innovation Path of the digital technology to promote the development of chemical fiber industry}

\subsection{Digital Technology Promotes Rapid Expansion of Chemical Fiber Industry}

Digital technologies include Internet, big data, artificial intelligence, block chain, cloud computing, Internet of Things and other technologies, which can promote the industry to reduce costs and increase growth. First of all, as a new type of production factor with strong versatility, digital technology can penetrate deeply into traditional production factors and "creatively destroy" the internal structure of traditional production mode, thus accelerating the improvement of industrial production efficiency and promoting the steady expansion of industrial scale. In addition, digital technology can also rapidly expand to all links in the chemical fiber industry chain with the lowest production cost. It can reduce production costs and open up trading links, and directly and indirectly save the production costs and trading costs of the chemical fiber industry, as well as promote the rapid expansion of the chemical fiber industry. Data research shows that since the 21 st century, the output scale development of China's digital industry and chemical fiber industry has shown an extremely consistent growth trend (Figure 1), and the industrial correlation degree reached 0.926 , indicating strong correlation of two industry, in addition, from the perspective of sub-sectors of industries, the digital technology industry includes computer, communication and other electronic equipment manufacturing, software and information technology service industries, etc. The correlation between the two industries and the chemical fiber industry is as high as 0.917 and 0.989 , which once again confirms the great influence of digital technology on chemical fiber industry.

\subsection{Development and innovation Path of Chemical Fiber Industry Promoted by Digital Technology}

The great contribution of digital technology lies in that it provides the fundamental power to change the inertia mode of all actors for the advancement of globalization and digitalization, and forms an optimal inertia modedigital technology economic paradigm. Under the influence of the new paradigm, the free flow of resources influenced by imitation will promote the mutual integration of traditional chemical fiber industry and digital industry, thus fundamentally forming "creative destruction" to the internal structure of chemical fiber industry, moreover the technical level and value creation ability of traditional industries in various fields such as products, technology, marketing and organization management will been improved, these will promote the high-end, specialized and personalized development of chemical fiber products, and eventually the production functions of this industry will realize the overall transition.

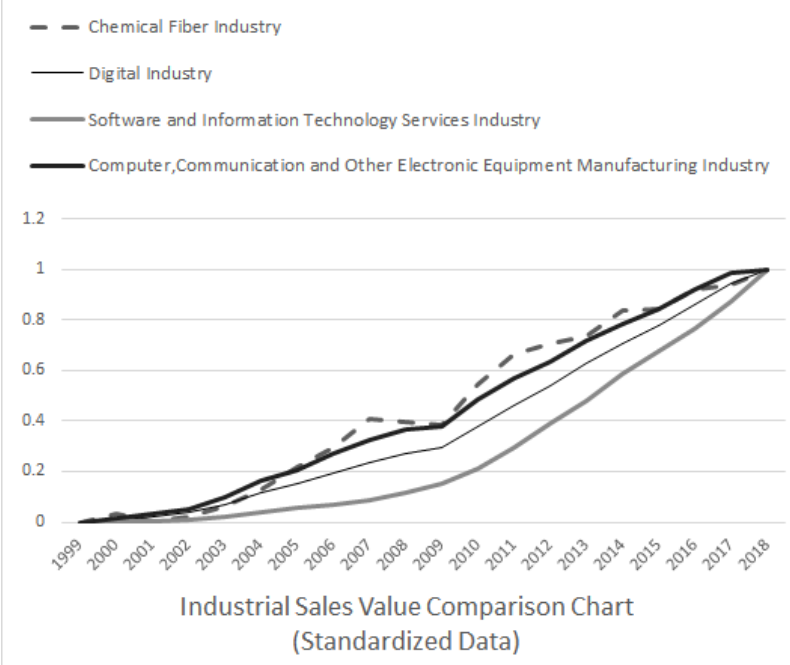

Fig1. 1999-2018 China's digital industry and chemical industry sales output value (Standardized Data)

\subsubsection{Digital Technology Promotes Product Innovation Ability of Chemical Fiber Industry}

The rapid expansion of demand for textiles and clothing has greatly stimulated the development of chemical fiber. The emergence of computer-aided design technology (CAD) and computer-aided manufacturing technology (CAM) and production process automation technology has greatly enhanced the manufacturing industry product development efficiency, Computer/contemporary Integrated Manufacturing Systems(CIMS) model has also begun to be applied in the production of chemical fiber industry.

From 1990 to 2018, new product research and development was accelerated, the number of new product development projects in the chemical fiber manufacturing industry expanded by more than 5 times, with an average growth rate of $18.75 \%$. The number of patent applications expanded by more than 100 times. In 2018, the sales revenue of new products accounted for $26.3 \%$ of the sales revenue, and the output of product innovation brought significant benefits.

In addition, the application of management systems such as ERP and SAP further improved the automatic design and production efficiency of new products in the 
chemical fiber industry, effectively shortened the research and development and production cycle of new products, reduced enterprise inventory, and improved the innovation efficiency of products.

\subsubsection{Digital technology promotes process innovation in chemical fiber industry}

Many chemical fiber industries have introduced information technology and automated production technology. The new production-oriented manufacturing execution system (MES) has accelerated the transformation of traditional processes, changed the original labor-intensive production methods, improved labor productivity, and the means of online inspection, remote diagnosis and operation \&maintenance functions improve the production efficiency of this industry.

\subsubsection{Digital Technology Drives Innovation of Raw Materials and Equipment in Chemical Fiber Industry}

"Green manufacturing" is gradually becoming the main development line of chemical fiber industry, green production technology and industry green certification for chemical fiber industry have provide green production materials and production technology for this industry. In addition, there are a wide variety of chemical fiber products, each product contains a variety of raw materials, the production management process is complex, the industry need to prepare a lot of equipment and accessories to ensure the normal production.

In recent years, the rapid development of chemical fiber equipment is the digital control and network communication. Through digital control, the precision and reliability of chemical fiber machinery and equipment are improved, and the operation process is stable. Polyester staple fiber devices, for example, the whole line of "200 tons of polyester staple fiber digitalized complete equipment" launched by Hengtian Heavy Industry Co., Ltd. adopts PLC control technology and network communication integration technology to form an online monitoring and management system for the whole production process, which makes process adjustment and fault display alarm. Online monitoring, information collection and processing are more complete, and the digital control level of the joint machine automation are all improved.

\subsubsection{Digital technology promotes the upgrading of marketing innovation in chemical fiber industry}

Digital technology has changed the circulation mode of traditional chemical fiber products. On the one hand, Internet technology and Mobile Internet technology have broken the geographical restrictions, New marketing model - network marketing, including information sharing platform and network sales can shorten the geographical distance between enterprises and customers, thus various resources can be optimized to gather and configure, and promote the circulation of chemical fiber products.

On the other hand, big data analysis and artificial intelligence technology can promote enterprises to implement precision marketing, and shorten the psychological distance between enterprises and customers. These technologies can promote the integration of chemical fiber enterprise resources, saves the cost of circulation, and improves the circulation efficiency of chemical fiber raw materials and products. The product circulation digitalization of chemical fiber products can make each production link penetrate each other, strengthen the connection of each part, and make the production information and market information the most effective match.

\subsubsection{Digital technology improves organizational and management capabilities in chemical fiber industry}

With the development of technologies such as the Internet, cloud computing, big data, the internet of things, artificial intelligence, and 5G, organizational and management capabilities have been improved rapidly, which has promoted the improvement of enterprise management capabilities. During special period of COVID-19, online office and telecommuting systems, such as DingTalk which developed by Alibaba, helped many enterprises resume production quickly. In addition, through the MIS, MRP, ERP, SAP, OA management system, chemical fiber companies integrate raw material procurement, supply, product manufacturing, finance, sales, quality management, laboratory management, business process management, product data management, inventory, distribution and transportation management, human resource management and periodic reporting systems, and improve the core competitiveness of the enterprise by standardizing management of enterprises, optimizing the resources of the enterprise from the scope of the supply chain, and improving the business processes of the enterprise.

\section{Quantitative Relationship Analysis of Digital Technology Promoting Development of Chemical Fiber Industry}

\subsection{Analysis Model}

This paper uses the Cobb Douglas production function, brings the digital industry output value into the production function, and test the quantitative relationship between the digital industry and the chemical fiber industry.

The model is as follows:

$\ln (Y)=\ln \mathrm{A}_{0}+\alpha \ln (L)+\beta \ln (K)+\gamma \ln (D)+\mu$

$Y$ stands for output value; $A_{0}$ stands for nontechnological progress elements; $L, K, D$ represents the labor force, capital and technological progress elements; $\alpha, \beta, \gamma$ represents the output elasticity of $L, K, D$ respectively.

\subsection{Data analysis}

Based on the availability and reliability of data, this paper 
selects the total output value of chemical fiber industry from 1999 to 2018 as the explanatory variables, and uses the total fixed assets value, the average number of employees and the total output value of digital industry as the explanatory variables for regression analysis. All the data come from China Statistical Yearbook, China Industrial Statistical Yearbook, China Science and Technology Statistical Yearbook and related databases. The regression results are as follows: $\ln (Y)=-3.37+0.67 \ln (L)+0.35 \ln (K)+0.58 \ln (D)$

Table1. REGRESSION RESULTS OF THE ESTIMATED MODLE

\begin{tabular}{|c|c|c|c|}
\hline Variable & Coefficient & t-Statistic & Prob. \\
\hline C & -3.372444 & -3.601743 & 0.0024 \\
\hline LOG(K) & 0.350421 & 2.742519 & 0.0145 \\
\hline LOG(L) & 0.671467 & 2.629610 & 0.0394 \\
\hline LOG(D) & 0.584572 & 8.620685 & 0.0000 \\
\hline
\end{tabular}

The output elasticity of labor in chemical fiber industry is higher than that of capital, and the unit output coefficient of digital technology industry is also higher than that of capital. This result shows that China's chemical fiber industry is still at the stage of labor-intensive industry, and at the same time, the promotion contribution brought by the development of digital industry has surpassed the capital factor, it shows that digital technology drives the development of chemical fiber industry.

In order to further explore the promotion mechanism of information technology on chemical fiber industry, this paper takes the five paths of Schumpeter's innovation theory as explanatory variables, and the digital industry output value growth rate as the dependent variable, and conducts regression analysis. In all the independent variables, technological innovation includes product innovation and process innovation, product innovation is mainly reflected in the sales revenue of new products, process innovation is not easy to quantify, but its effect can be reflected in the sales revenue of new products. This article takes the ratio of new product sales revenue to main business revenue represents the efficiency of technological innovation Y1; Proportion of research and development expenditure on instruments and equipment to asset expenditurere presents equipment update rate $\mathrm{Y} 2$; marketing expense rate presents presents Y3; management expense rate presents the organizational innovation Y4.

Table2. QUANTITAVE RELATIONSHIP BETWEEN INDUSTRIES

\begin{tabular}{|c|c|c|c|}
\hline Variable & Coefficient & t-Statistic & Prob. \\
\hline Y1 & 0.263 & 5.734 & 0.000 \\
\hline Y2 & 0.737 & 16.071 & 0.000 \\
\hline Y3 & -0.013 & -3.544 & 0.002 \\
\hline Y4 & -0.047 & -4.006 & 0.000 \\
\hline
\end{tabular}

According to the regression results, for every percentage point increase in the output of digital industry, technical innovation rate, equipment progress rate of chemical fiber industry, will increase by $0.263 \%, 0.737 \%$, the marketing rate and management rate will reduce $0.013 \%$ and $0.047 \%$ correspondingly. These data show that, with the development of the digital industry, the level of new product research and development, technical progress and equipment update in the chemical fiber industry are steadily increasing, and both marketing expense ratio and management expense ratio of the industry show a downward trend.

\section{4 summary}

According to the characteristics of chemical fiber production and the changes in production methods, it has become a trend for chemical fiber mechanical products to have large capacity, continuity, automation and modular design of mechanical products. To improve the application level of digital technology in chemical fiber industry and to apply digital technology and corresponding management methods to the whole process management of chemical fiber manufacturing are the current development direction of chemical fiber industry.

Innovation is the power and source for the industry to maintain its competitive advantage and develop constantly Digital technology promotes the development and progress of chemical fiber industry through five innovation approaches. It is necessary to apply digital technology to continuously improve the technological innovation level of chemical fiber industrial equipment and improve the efficiency of new product research and development. Empirical study results show that, when equipment update rate increases one unit, the output will increase 0.737 units, when new product development efficiency increases one unit, its output increased 0.263 units. Chemical fiber industry output growth depends more on their equipment update progress. Therefore, in order to achieve further sustainable development of China's chemical fiber industry, we should vigorously promote the informationization, intelligence, digitization and automation of traditional industrial chemical fiber equipment, thereby improving labor productivity, stabilizing and improving product quality. In order to the future development of the chemical fiber industry, we should promote the deep integration of digital technology and chemical fiber industry, enhance the independent innovation capability of enterprises, and promote the development of China's chemical fiber from the current labor-intensive to digital-based and efficient transformation.

\section{References}

1. Lu Jianxin, Lu Jinpeng, “Advantages and disadvantages of China's chemical fiber export trade and countermeasures", Polyester Industry,2018, vol.31, pp.1-7.

2. Qian Bozhang, "The '13th five-year' chemical fiber industry will enter a period of low speed growth", Synthetic Fiber, 2015, vol.7, pp.53-53.

3. Duan Xiaoping, Wu Wenjing, "Research on the development trend of China's chemical fiber industry", Textile Science Research, 2018, vol.2, pp.26-31.

4. Li Xiaoyi, “' 'going global' of chemical fiber industry 
is a heavy responsibility due to the bottleneck of development", China Fiber Inspection, 2010.

5. Hao Jie, "Internet platform promotes the upgrading of chemical fiber industry", China Economic Information, 2017.

6. Gallant, "Application of information technology in chemical fiber industry", Synthesis Technology and Application, 2012, vol.1, pp.:30-32.

7. Sun Xiaojun, "Research on the application of production management information system in jimeng acrylic fiber company", Changchun, Jilin: Jilin university, 2011.

8. Zhao Weiwei, "Exploration and research on ERP system of chemical fiber production enterprises", Dalian, Liaoning: Dalian Polytechnic University, 2016.

9. $\mathrm{Hu}$ Yuezhong, "Application of information technology in equipment management business process reengineering of jilin chemical fiber group", Changchun, Jilin: Jilin university, 2007.

10. Jilin Chemical Fibre Co., Ltd, "Research on business process reengineering", Changchun, Jilin: Jilin university, 2011. 